\title{
Aislamiento e Identificación de Consorcios Bacterianos Acidófilos y Ferroso - Oxidantes de Entornos Mineros para Procesos de Biolixiviación de Calcopirita
}

\author{
Isolation and Identification of Acidophilic and Ferrous-oxidizing Bacterial Consortia \\ From Mining Environments for Chalcopyrite Bioleaching Processes
}

Jean Piere Quiliche Duran ${ }^{1}$, Pedro Rodríguez Grados ${ }^{1}$, Anthony Cortez Lázaro ${ }^{1}$, Mishell Silva Vergara ${ }^{1}$, Eduardo Benites Requena ${ }^{2}$, Alfonzo Díaz Guzmán” ${ }^{3}$, Magna Valverde Mendoza ${ }^{4}$

\begin{abstract}
RESUMEN
Objetivo: Aislar e identificar consorcios de bacterias acidofilas y ferroso-oxidante procedentes de suelo y charcos de agua en los alrededores de la Compañía Minera Huancapeti-Ancashy el crecimiento en calcopirita. Materiales y métodos: Se tomó 17 muestras de suelo y 13 de charcos, para el aislamiento de los consorcios se utilizó el medio quimiolitótrofos $\mathrm{ABS} 1 \mathrm{X}$ suplementado con $50 \mathrm{~mm}$ de sulfato ferroso heptahidratado $\left(\mathrm{FeSO}_{4}\right.$. $7 \mathrm{H}_{2} \mathrm{O}$ ) e identificando con el microscopio compuesto las morfologías de los consorcios en una cámara de Neubauer y el crecimiento de consorciose evaluó en $100 \mathrm{ml}$ de medio ABS1X con 10 gramos calcopirita $\left(\mathrm{CuFeS}_{2}\right)$ al $15 \%$ de pureza las condiciones fueron en estático a $31^{\circ} \mathrm{C} \mathrm{y} \mathrm{pH} \mathrm{2.} \mathrm{Resultados:} \mathrm{Se} \mathrm{aislaron} 15$ consorcios acidofilos y ferroso-oxidantes de morfología en bacilos y cocos de diferentes dimensiones, hubo crecimiento en calcopirita hasta $1 \times 10^{8}$ bacterias por mililitro. Conclusión: Los consorcios aislados crecieron a pH 2 y a $31^{\circ} \mathrm{Ccon}$ el medio ABS1X tanto con sulfato ferroso heptahidratado y calcopirita.
\end{abstract}

Palabras clave: Calcopirita, ferroso-oxidantes, biolixiviación.

\begin{abstract}
Objective: To isolate and identifyconsortia of acidophilic and ferrous-oxidant bacteria from soil and pools of wateraround the Huancapeti-Ancash Mining Company and the growth in chalcopyrite.Materials and methods:Seed and soil samplesweretaken from 17 pools. For the isolation of the consortium, the chemilithotrophosphate ABS1X mediumsupplementedwith $50 \mathrm{mM}$ of ferrous sulfate heptahydrate (FeSO4.7H2O) wasused and the morphologies of the consortia In a Neubauer chamber and the growth of consortium wase valuated in $100 \mathrm{ml}$ of ABS1X mediumwith 10 gramschalcopyrite (CuFeS2) at 15\% purity conditions were in static at $31^{\circ} \mathrm{C}$ and $\mathrm{pH}$ 2.Results: 15 consortiawere isolated acidophilus and Ferrous-oxidants of morphology in bacilli and cocci of different dimensions, therewas growth in chalcopyrite up to $1 \times 108$ bacteria per milliliter.Conclusion:The isolated consortiagrew at $\mathrm{pH} 2$ and at $31^{\circ} \mathrm{C}$ with the $\mathrm{ABS} 1 \mathrm{X}$ mediumwithbothferrous sulfate heptahydrate and chalcopyrite.
\end{abstract}

Keywords: Chalcopyrite, ferrous-oxidants, bioleaching.

\footnotetext{
${ }^{1}$ Estudiantes. Facultad de Ciencias. Universidad Nacional José Faustino Sánchez Carrión. Lima - Perú Email. Jean_19_2014@hotmail.com

${ }^{2}$ Docente. Facultad de Ciencias. Universidad Nacional José Faustino Sánchez Carrión.

${ }^{3}$ Docente. Facultad de Ingeniería Agraria, Industrias Alimentarias y Ambiental. Universidad Nacional José Faustino Sánchez Carrión. Email: ingenieroadg@outlook.com

${ }^{4}$ Docente. Facultad de Ciencias Contables y Financieras. Universidad Nacional José Faustino Sánchez Carrión
} 


\section{INTRODUCCIÓN}

La minería es la principal fuente de ingresos del Perú así que el estudio de nuevas alternativas para disminuir la contaminación generada por la extracción de minerales podría ser una buena respuesta frente a este problema.

Una de las soluciones es el uso de bacterias acidofilas para realizar biolixiviación, ellos se encuentran principalmente en donde está el mineral de interés y muestran una adaptación única frente al medio ácido.

El valor agregado que genera la utilización de esta alternativa biológica se representa en mejorar la calidad de vida de los mineros y del ecosistema que rodea esta industria (Agudelo, Betancur y Largo, 2002).

La lixiviación bacteriana, también conocida como biolixiviación o biooxidación de sulfuros, puede ser definida como un proceso natural de disoluciones que resulta de la acción de un grupo de bacterias específicas para lixiviar o extraer, metales o concentrados minerales presentes en las minas. El producto final de la biolixiviación es una solución acida que contiene el metal en su forma soluble. (Agudelo, Betancur y Largo, 2002).

Dependiendo de la composición del mineral sulfurado, la biolixiviación es una alternativa ventajosa con respecto a las tecnologías pirometalurgicas. Si bien la lixiviación bacteriana es más lenta que la pirometalurgia en cuanto a la velocidad de obtención del metal, demanda menores inversiones de capital y menores costos de operación. Además se presenta como una tecnología más limpia que las practicadas comúnmente, debido a que no se emite $\mathrm{SO}_{2}$ al ambiente en su periodo de operación. (Ballester, 2005).

La calcopirita $\left(\mathrm{CuFeS}_{2}\right)$ es la fuente primaria de cobre en el mundo, representando el $70 \%$ de las reservas. Su beneficio se hace generalmente por pirometalurgia; sin embargo, esta tecnología genera contaminaciones de $\mathrm{SO}_{2}$, principal causante de las lluvias ácidas. (Dutrizac, 1981; Rivadeneira, 2006).

En el género Acidithiobacillus se han estudiado las Acidithiobacillus thiooxidans, Acidithiobacillus caldus y Acidithiobacillus ferroxidans; son caracterizadas por su evolución favorable a temperaturas entre 28 y 35 ${ }^{\circ} \mathrm{C}$, utilizan $\mathrm{CO}_{2}$ como fuente de carbono y obtienen energía de la oxidación del azufre, hierro y sulfuros metálicos.(Silverman \& Lundgren, 1959).

Aislados de la Mina Tamboraque-Perú encontraron microorganismos acidófilos y quimilitotróficos oxidantes de fierro y/o sulfatos observando solo bacilos Gram negativos con morfología correspondiente a Acidithiobacillus y Leptospirillum (Quintana et al, 2002).

La A. ferrooxidans es la bacteria más ampliamente estudiada en procesos de biolixiviación. Aislada por primera vez de drenajes ácidos en minas de carbón (Colmer y Hinkle, 1947)
El sistema de oxidación de hierro (II) en T. ferroxidans está relacionado con la membrana celular. La enzima ferrooxidante clave parece ser la citocromo c-Fe+2 oxido reductasa; en el proceso también interviene en la coenzima $Q$ y el citocromo a, quienes realizan el transporte de electrones. Existe una proteína de cobre, que servirá como el aceptor inicial de electrones de la oxidación de Fe (II): Rusticianina, la que es fácilmente reducida por Fe (II) (Guerrero, 1998), y de ella depende que la bacteria reduzca el sulfato por asimilación, a lo cual despolariza su membrana para permitir al ion ferroso enlazara sitios de transporte de la proteína y funciona como ligando para la síntesis de complejos susceptibles de oxidación a pH menor de 3.5 (Boon y Heijnen, 1998).

Acidithiobacillus ferrivorans es único entre la Acidithiobacillus en que es capaz de crecer a temperaturas cerca $0 \circ \mathrm{C}$ y se denomina 'psicrotolerantes' (Hallberg, González-Toril y Johnson 2010).

\section{MATERIAL Y MÉTODOS}

Este proyecto de investigación se desarrolló el método prospectivo y descriptivo. Para mostrar aspectos importante de las bacterias lixiviadoras. Entonces no se usara un modelo probabilístico.

\section{Toma y transporte de las muestras}

El lugar de muestreo se llevó a cabo en alrededores de la Compañía Minera Huancapeti S.A.C. ubicada en la provincia de Recuay en el departamento de Ancash, lo primero que se hizo fue escoger dentro del área 30 zonas de muestreo en el año 2016.

Las muestras se recolectaron en frascos de vidrio estériles 17 muestras cada una de $100 \mathrm{ml}$ de agua de charcos y 13 de 100 gramos de suelo, en un intervalo de tiempo de 5 a 10 minutos, 17 muestras se recolectaron de suelo ty 13 muestras liquidas, ubicándonos por cada muestreo con un GPS Garmin.

El transporte de las muestras se realizó a temperatura ambiente se midió la temperatura y $\mathrm{pH}$ por cada punto de muestreo. El análisis se desarrolló en el laboratorio de Multifuncional de Biología de la Universidad José Faustino Sánchez Carrión.

\section{Medio de cultivo ABS1X con 50mM de Fe (II)}

El medio seleccionado para el estudio fue el medio ABS1X. Para la preparación del medio ABS1X ( $/ \mathrm{L} / \mathrm{L})$ se utilizaron: $0.15 \mathrm{~g}\left(\mathrm{NH}_{4}\right)_{2} \mathrm{SO}_{4}, 0.05 \mathrm{~g}$ de $\mathrm{KH}_{2} \mathrm{PO}_{4}, 0.066 \mathrm{~g}$ $\mathrm{Na}_{2} \mathrm{SO}_{4}, 0.05 \mathrm{~g}$ de KCl, $0.5 \mathrm{~g} \mathrm{MgSO}_{4} .7 \mathrm{H}_{2} \mathrm{O}$ y $0.014 \mathrm{~g} \mathrm{Ca}$ $\left(\mathrm{NO}_{3}\right)_{2} .4 \mathrm{H}_{2} \mathrm{O}$. Se disolvieron las sales en 1 litro de agua destilada se ajustó el $\mathrm{pH}$ final de 2 con $\mathrm{H}_{2} \mathrm{SO}_{4} 10$ Ny se esterilizó en un autoclave a $121^{\circ} \mathrm{C}$ y 15 libras de presión por 15 minutos, posteriormente se añadió $50 \mathrm{mM}$ de $\mathrm{FeSO}_{4} \cdot 7 \mathrm{H}_{2} \mathrm{O}$ esterilizado por filtros de membrana $0.22 \mu \mathrm{m}$.

\section{Preparación y siembra de las muestras}

Las muestras liquidas se usó un inoculo de $20 \%$ y en las muestras de suelo se generó una suspensión con agua acida $\mathrm{pH} 2$, dejándose reposar, posteriormente se tomó el sobrenadante, ambos en 100ml de ABS1X 
con $\mathrm{FeSO}_{4} \cdot 7 \mathrm{H}_{2} \mathrm{O}$, las condiciones de incubación fueron a $31^{\circ} \mathrm{C}$ y en estático por 2 semanas. Luego se prosiguió a realizar resiembras hasta la purificación del consorcio.

Tabla 1: Resiembras sucesivas con relación al cambio de viraje como respuesta del crecimiento bacteriano.

\begin{tabular}{lc}
\hline Resiembras & Tiempo de Incubación \\
\hline Siembra & 15 días \\
$1^{\circ}$ Resiembra & 10 días \\
$2^{\circ}$ Resiembra & 7 días \\
$3^{\circ}$ Resiembra & 7 días \\
$4^{\circ}$ Resiembra & 5 días \\
$5^{\circ}$ Resiembra & 5 días \\
$6^{\circ}$ Resiembra & 4 días \\
$7^{\circ}$ Resiembra & 4 días \\
$8^{\circ}$ Resiembra & 4 días \\
$9^{\circ}$ Resiembra &
\end{tabular}

Crecimiento en ABS1X con Calcopirita

Se usó calcopirita al 15\% de pureza añadido en 100ml de ABS1X las condiciones de incubación fueron a temperatura $31^{\circ} \mathrm{C}, \mathrm{pH} 2$ y aireación externa. También se le hizo un seguimiento de la concentración bacteriana en cámara de Neubauer.

Identificación microscópica

Se observó morfología de las bacterias en una cámara de Neubauer para cada consorcio y se consideró una escala de tamaño.

\section{RESULTADOS}

\section{Toma de muestras}

Fueron tomadas 30 muestras en total en diferentes puntos en alrededores de la mina Huancapeti S.A.C que se encuentra ubicada a 4380 m.s.n.m. (Figura 1), las condiciones de las muestras encontradas fueron de $14-17^{\circ} \mathrm{C}$ y $\mathrm{pH} 5.041$ a 6.660 .

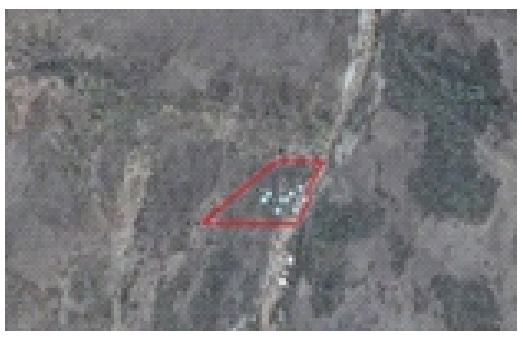

Figura 1: Se observa los puntos donde se obtuvieron las muestras liquidas y de suelos en la Mina Huancapeti S.A.C.

\section{Aislamiento de consorcios}

Se obtuvo 15 consorcios bacterianos que tenían la capacidad de oxidar ferroso y crecían a condiciones acidas.

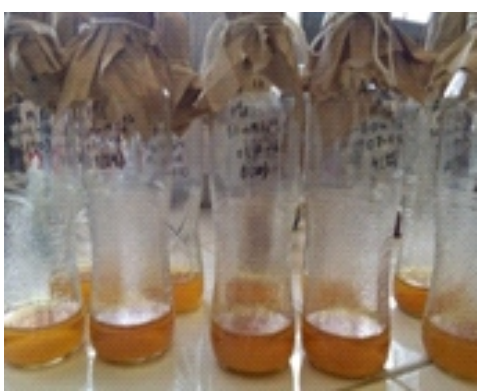

Figura 2: Se observa los consorcios crecidos en ABS1X con $\mathrm{FeSO}_{4} \cdot 7 \mathrm{H}_{2} \mathrm{O}$, presencia de férrico de color anaranjado por la oxidación del ferroso.

Identificación microscópica

A continuación, en la tabla 2 se muestra la morfología observadas en cámara de Neubauer de cada consorcio.

Tabla 2: Se observa morfología de los consorcios aislados vistos en cámara de Neubauer.

\begin{tabular}{ll}
\hline Consorcio & \multicolumn{1}{c}{ Morfología } \\
\hline M1 & Bacilos largos y cocos \\
M2 & Bacilos medianos y cocos \\
M4 & Bacilos medianos y cocos \\
M5 & Bacilos pequeños y cocos \\
M6 & Bacilos pequeños \\
M8 & Bacilos medianos y pequeños \\
M9 & Bacilos pequeños \\
M10 & Bacilos largos \\
M13 & Bacilos largos y pequeños \\
M16 & Bacilos largos \\
M17 & Bacilos pequeños \\
M22 & Bacilos largos \\
M23 & Bacilos pequeños \\
M24 & Bacilos medianos y cocos \\
\hline
\end{tabular}




\section{Crecimiento en Calcopirita}

A todos los consorcios se le hizo un seguimiento de su concentración en función de bacterias por mililitro hasta llegar $1 \times 10^{8}$ aproximadamente y además el cambio de viraje a color anaranjado por presencia de férrico como indicador de crecimiento que se observó en un periodo de 10 a 20 días.

\section{DISCUSIÓN}

Resultados obtenidos en experimentos previos demuestran que los microorganismos que participan en la biolixiviación poseen características especiales de crecimiento y supervivencia tales como su capacidad de crecer a pH ácido (Agudelo, Betancur y Largo ,2002; Boon y Heijnen, 1998 \& Guerrero, 1998), a temperaturas entre 2 a $37^{\circ} \mathrm{C}$ (mesófilos), a temperaturas mayores entre $45-50^{\circ} \mathrm{C}$ (termófilos moderados) llegando hasta temperaturas de $70{ }^{\circ} \mathrm{C}$ (termófilos extremos). (Dopson, 1999).

Arias et al., 2012 en su aislamiento en unidades mineras de Julcani y Recuperada-Huancavelica se encontraron bacterias Gram negativas de forma bacilar.

Los estudios de Bozdemir, Durusoy, Erincin y Yürüm., 1996; Rawling, Tributsch, y Hansford, 1999; Daoud y Karamanev, 2006 ;los microorganismos comúnmente usados en la lixiviación de sulfuros, Acidithiobacillus ferrooxidans y Acidithiobacillus thiooxidans metálicos son mesófilos, se presentan en intervalos de temperatura entre los 20 y $45^{\circ} \mathrm{C}$; los acidófilos viven en ambientes cuya acidez puede bajar hasta $\mathrm{pH}<1$, y los quimiolitótrofos, que derivan la energía para llevar a cabo sus procesos metabólicos de compuestos inorgánicos , los cuales obtienen la energía necesaria de la oxidación de compuestos reducidos del azufre y del $\mathrm{Fe}^{2+} a \mathrm{Fe}^{3+}$.

Para el caso de la calcopirita, el crecimiento fue bueno de los consorcios a $\mathrm{pH}$ ácido pero lento, asi como estudios por Bevilaqua, Leite, García \& Touvinen., 2002; Meruane y Vargas, 2003 los cuales aportan que primero se debería adaptar los consorcios a la calcopirita para proseguir con concentraciones definidas para el proceso de biolixiviación.

\section{CONCLUSIONES}

Los consorcios crecieron a $\mathrm{pH} 2$ y a $31 \mathrm{C}^{\circ}$ con el medio ABS1X tanto con sulfato ferroso heptahidratado y calcopirita.

\section{AGRADECIMIENTO}

Nuestro sincero agradecimiento al jefe del laboratorio Multifuncional de Biología Luis Alberto Huayna Dueñas por su apoyo en el transcurso de la investigación.

\section{REFERENCIAS BIBLIOGRAFICAS}

Agudelo, J., Betancur, U. y Largo, M. (2002). Biolixiviación de minerales sulfurosos. Revista Facultad de Ingeniera. Universidad de Antioquia, p.27.

Arias, A., Rodriguez, C., Ramirez, P., Nonones, E . , Salazar, D., Gil, J., Paredes, R. y Jamanca, G. (2012). Aislamiento de bacterias acidofilas a partirdeldrenaje acido proveniente de las inmediaciones a las unidades mineras de Julcani y Recuperada, Huancavelica. 15 (30), $59-66$.

Ballester, A. (2005). Mecanismo de biolixiviación. Valparaíso, Chile: Ediciones Universitarias de Valparaíso, $\quad$ 9-24.

Bevilaqua, D., Leite, A., García, Jr. O., $\quad$ Touvinen, O. (2002). Oxidation of $\mathrm{C} \mathrm{h}$ a I c o p y r i te b y Acidihiobacillus ferrooxidans and Acidithiobacillus thiooxidans in shake flasks, Process Biochemistry, 38:587-592.

Bozdemir, T., Durusoy, T., Erincin, E. \& Yürüm, $\quad Y \quad$. (1996). Biodesulfurization of Turkish I i g $\mathrm{n}$ i t e s . Fuel, 75 (13): 1596-1600.

Boon, M. \& Heijnen, J. (1998). Chemical ox i d a t i o $n$ kinetics of pyrite in bioleaching processes. Hydrometallurgy, 48, 27-41.

Colmer, A.R. y Hinkle, M.E. (1947). The Role of Microorganisms in Acid Mine Drainage: A Preliminary Report, 253 - 256.

Daoud, J. \& Karamanev, D. (2006). Formation o f coal jarosite during $\mathrm{Fe}^{2+}$ oxidation by Acidithiobacillus ferrooxidans. Mineral Engineering, 19: 960-967.

Dopson, M. (1999). Potencial role of Thiobacillus caldus in arsenopyrite bioleaching. Applied and environmental microbiology, 36-40. 
Dutrizac, J.E. (1981). The dissolution of chalcopyrite in ferric sulfate and ferric chloride media. Met. Trans, 12: $371-$ 378.

Guerrero, R. (1998). Recuperación de valores metálicos por vía biohidrometalurgica. Universidad Nacional del Centro del Perú, Huancayo, p.7.

Hallberg, K.B., González-Toril, E. y Johnson, B. D . (2010). Acidithiobacillus ferrivorans, s p . nov.; facultatively anaerobic, psychrotolerant iron-, and sulfur- oxidizing acidophiles isolated from metal mine-impacted environments.

Meruane, G., Vargas, T. (2003). Bacterial oxidation of ferrous iron by Acidithiobacillus ferrooxidans in the $\mathrm{pH}$ range $2,5-7,0$ Hydrometallurgy, $71 \quad$ (1-2): 149-158.

Quintana, M., Ly, M., Bauer, J., Montoya, Y., Comallonga, L., Vassel, B., Espinoza, $\quad$ M . ,
Espinoza, J. (2002). Aislamiento y caracterización molecular de microorganismos biooxidantes de arsenopirita, 2: $142-146$.

Rawlings, D. E., Tributsch, H. \& Hansford, G. (1999). Reasons why 'Leptospirillum' Ii ke species rather than Thiobacillus ferrooxidans are the dominant iron- oxidizing bacteria in many commercial processes for the biooxidation of pyrite and related ores. Microbiology, 145, 513.

Rivadeneira, J. (2006). Introduction. Mining innovation in Latin America Report. Publication via on-line (

http://www.mininginnovation.cl/content.htm). Santiago, Chile, 6-7.

Silverman, M.P. \& Lundgren, D.G. (1959). Studies on the chemoautotrophic iron bacterium Acidithiobacillus ferrooxidans. I. An improved medium and a harvesting procedure for securing high cellular yields, J. Bacteriol, 77, 642-647. 